\title{
Preliminary research for low-cost particulate matter sensor network
}

\author{
Csongor Báthory ${ }^{1, *}$, Márton L. Kiss ${ }^{2}$, Attila Trohák $^{2}$, Zsolt $_{\text {Dobó }}{ }^{1}$, and Arpád Bence Palotás ${ }^{1}$ \\ ${ }^{1}$ University of Miskolc (ME), Institute of Energy and Quality Affairs, \\ 3515 Miskolc-Egyetemváros, Hungary \\ ${ }^{2}$ University of Miskolc (ME), Institute of Automation and Infocommunication, \\ 3515 Miskolc-Egyetemváros, Hungary
}

\begin{abstract}
Low-cost particulate matter (PM) sensors may be suitable for indicative air quality measurements thanks to their small dimensions and high spatial resolution. Three different sensor types were selected for investigation in this study with specific focus on a Honeywell HPMA115S0 sensor to find out its usability at outdoors, perform load and long-term tests. The load test showed that the sensor calculates $\mathrm{PM}_{10}$ based on measured $\mathrm{PM}_{2.5}$ values. The analysis shows a break in calculation method at $25 \mu \mathrm{g} / \mathrm{m}^{3}$ $\mathrm{PM}_{2.5}$, and the calculation method for $\mathrm{PM}_{10}$ varies from $25 \mu \mathrm{g} / \mathrm{m}^{3}$ by around $81 \mu \mathrm{g} / \mathrm{m}^{3}$. Parallel test performed with different sensor types has shown that the protective cover formed by lamellar exterior does not affect the accuracy of the sensors, no accumulation or loss of sensitivity occurs. Long-term measurements have shown that the concentration values measured by the Honeywell sensor during outdoor measurements require humidity compensation, over $90 \%$ relative humidity $(\mathrm{RH})$ the Pearson correlation coefficient $(\mathrm{R})$ between the reference and sensor $\mathrm{PM}_{2.5}$ concentrations decreased by 0.3 .
\end{abstract}

\section{Introduction}

PM concentration is one of the most important indicator of ambient air quality due to its impact on human health [1], visibility [2] and climate [3, 4]. From a health point of view, the negative health effects of elevated PM concentrations include arrhythmia, heart disease, lung cancer and mortality [5]. Because of these serious consequences, the ambient concentrations of $\mathrm{PM}_{10}$ and $\mathrm{PM}_{2.5}$ are regulated by The United States Environmental Protection Agency (US EPA [6]), the European Union (Air Quality Directive 2008/50/EC, AQD [7]) and the Hungarian Legislation (306/2010 (XII 23.) Government Decree on Air Protection [8]), but the World Health Organization (WHO [9]) also makes recommendations to that. Compliance with the regulations is checked by the environmental authorities in accordance with the Federal Reference Methods (FRM [10]) or the Air Quality Directive (AQD [7]). According to the standards, the appropriate size of dust is collected by pre-separating and filtering, and the daily and annual average concentrations of PM are calculated by gravimetric method,

\footnotetext{
${ }^{*}$ Corresponding author: csongor.bathory@uni-miskolc.hu
} 
based on EN12341:2014 standard [11]. Beside FRM, there are so-called Federal-Equivalent Methods (FEM [10]) approved by EPA, which can provide hourly, quarter hourly and even minutely data for measuring PM concentration [12]. FEM-specific methods operate according to a measurement principle different from the gravimetric method of the FRM and EN12341:2014, such as optical detection [13], beta-ray absorption [14] or Tapered Element Oscillating Microbalance (TEOM) [15]), complying with strict requirements.

FEM devices cost almost the same as the FRM devices, but they are easier to handle and more practical for continuous monitoring. There are laboratory calibrated desktop and handheld devices (Calibrated Portable Devices, CPD) on the market which are suitable for detecting PM, and the price is one order of magnitude lower than the previous ones, but the results are not accepted in official procedures. Low Cost Sensors (LCS) are available with significantly lower price $(<\$ 50)$, some of which are calibrated, but their calibration is not well documented and unreliable. Fig. 1 shows the classification of PM measurement devices.
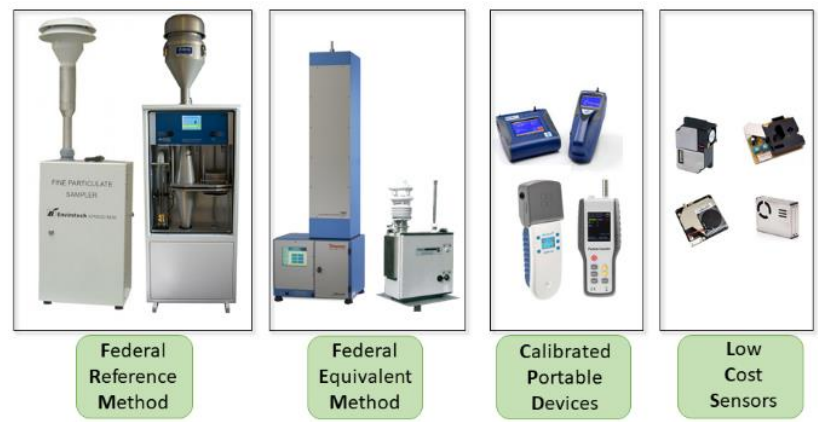

Fig. 1. Classification of PM measurement devices.

AQD gives the opportunity to use complementary techniques such as air quality models and indicative measurements. Low-cost dust sensors may be suitable for such indicative measurements. The legal and procedural background is currently being developed by EU Delegated Working Groups (CEN/TC 264/WG42 [16]). Despite many studies, there are still many unanswered questions about the accuracy, reliability, consistency and reproducibility of these sensors [17-23] and the environmental impacts are not fully clear. For example, humidity is an important parameter in the analysis of sensor values, as FEM and FRM devices provide PM concentration values at constant 50\% RH [19-21].

According to the AQD, indicative measurements are measurements which fulfill less strict data quality objectives compared to fixed measurement methods. LCS belong to the group of indicative measurements, because they operate with accuracy of $10-15 \%$ under ideal conditions. In addition, the meteorological characteristics may further increase the error of measurement; however, indicative measurements can be carried out with them. Commercially available low-cost sensors provide concentration values for $\mathrm{PM}_{10}, \mathrm{PM}_{2.5}$ and even $\mathrm{PM}_{1}$. According to our previous research, fan-mounted sensors were preferred during tests, because the amount of air sucked in is less influenced by the weather and they are more reliable. Similar conclusion was reported by Canu et al. [24]. The main goal of this paper is to test three different types of sensors from various aspects including reproducibility, design variations, sensors comparison and humidity influence. 


\section{Materials and methods}

Three sensors were selected for investigation in this study, the main parameters are summarized in Table 1. Plantower can measure more than one particle size at a time, providing data on the number of particles less than $0.3,0.5,1,2.5,5$, and $10 \mu \mathrm{m}$ in a volume of 0.1 liters, plus concentrations of $\mathrm{PM}_{1}, \mathrm{PM}_{2.5}$ and $\mathrm{PM}_{10}$ in $\mu \mathrm{g} / \mathrm{m}^{3}$. Winsen gives $\mathrm{PM}_{1}$, $\mathrm{PM}_{2.5}$ and $\mathrm{PM}_{10}$, while Honeywell gives $\mathrm{PM}_{2.5}$ and $\mathrm{PM}_{10}$ in $\mu \mathrm{g} / \mathrm{m}^{3}$. Plantower shows extreme humidity range of $0-99 \% \mathrm{RH}$, but non-condensing conditions are required for all the three sensor types. The upper RH limit of Honeywell is $95 \%$ but some studies reveal that the humidity impacts the readings from $60 \%[25], 70-75 \%[26,27]$ and $85-95 \%[28,29]$.

Table 1. Main parameters of sensors selected for investigation.

\begin{tabular}{|c|c|c|c|}
\hline Brand, Name & Plantower & Winsen & Honeywell \\
\hline Type & PMS7003 & ZH03 & HPMA115S0 \\
\hline $\mathrm{PM}_{1}$ & $\mathrm{x}$ & $\mathrm{x}$ & - \\
\hline $\mathrm{PM}_{2.5}$ & $\mathrm{x}$ & $\mathrm{x}$ & $\mathrm{x}$ \\
\hline $\mathrm{PM}_{10}$ & $\mathrm{x}$ & $\mathrm{x}$ & $\mathrm{x}$ \\
\hline Light source & laser & laser & laser \\
\hline Flow provider & fan & fan & fan \\
\hline Limit of detection $[\mu \mathrm{m}]$ & 0,3 & 0,3 & - \\
\hline Measurement range $\left[\mu \mathrm{g} / \mathrm{m}^{3}\right]$ & $0-1000$ & $0-1000$ & $0-1000$ \\
\hline Working Humidity $[\% \mathrm{RH}]$ & $0-99$ & $0-85$ & $0-95$ \\
\hline Working Temperature $\left[{ }^{\circ} \mathrm{C}\right]$ & $-10-60$ & $-10-50$ & $-10-50$ \\
\hline
\end{tabular}

An earlier study found that the firmware of Nova SDS011, which is another type of $\mathrm{PM}_{2.5}$ and $\mathrm{PM}_{10}$ sensor, calculates the $\mathrm{PM}_{10}$ concentration from $\mathrm{PM}_{2.5}$ values by an unknown interpolation [43]. So, based on the datasheets, it is not clear yet that in what range makes the sensor real measurement and how much it relies on calculations. The $\mathrm{PM}_{10}$ calculation method was determined in case of Honeywell sensor in the full measurement range. A test was carried out with two Honeywell type sensors in a cigarette smoky open-air environment. The typical particle size of cigarette smoke is below $1 \mu \mathrm{m}$ [44], other PM sources were not significant. The average temperature during the test was $28 \pm 0.1{ }^{\circ} \mathrm{C}$ and the relative humidity was $61 \pm 2.1 \%$. The results of the two Honeywell sensor cigarette smoke tests were averaged to reduce sensor uncertainty. Inspired by meteorological stations a lamellar protective cover was made, in which the individual types of sensor can be fixed in a convertible manner. For comparability, two of the three types of PM sensors were operated by two STM32 microcontrollers. Temperature and relative humidity data were collected by BME280 sensor, which is also an LCS. Data from sensors was recorded by a Raspberry PI $3 \mathrm{~B}+$ microcontroller in every 6 seconds. Measurements were made on the 1st floor balcony at Miskolc, Táncsics square residential building, about 50 meters from the main road. In this area, air pollutants typically originate from the main road and from the surrounding household fires, the latter is more significant during heating season. A series of one-hour period measurements were conducted with different sensors to investigate the influence of cover as well.

Comparative measurements were carried out without a calibrated reference device, so the measurement without the protective cover serves as a reference. The Honeywell type sensor with the tested protective cover was installed at the Országos Légszennyezettségi Méröhálózat (National air pollution measurement network of Hungary, OLM) measuring station of Miskolc, Alföldi Street. The sensor was placed at the same height as the inlet of the installed monitoring stations GRIMM EDM 180, which was the reference FEM PM device during the 13 days long measurement. 


\section{Results and discussion}

To determine the effect of the protective cover, changes in the measured values of the same type of sensors during hourly series were compared. A total of 12 measurements were performed. Fig. 2a shows the differences of Honeywell sensors in full range, so outliers are displayed $\left(-24.3 \mu \mathrm{g} / \mathrm{m}^{3}\right.$ and $\left.-61.9 \mu \mathrm{g} / \mathrm{m}^{3}\right)$.
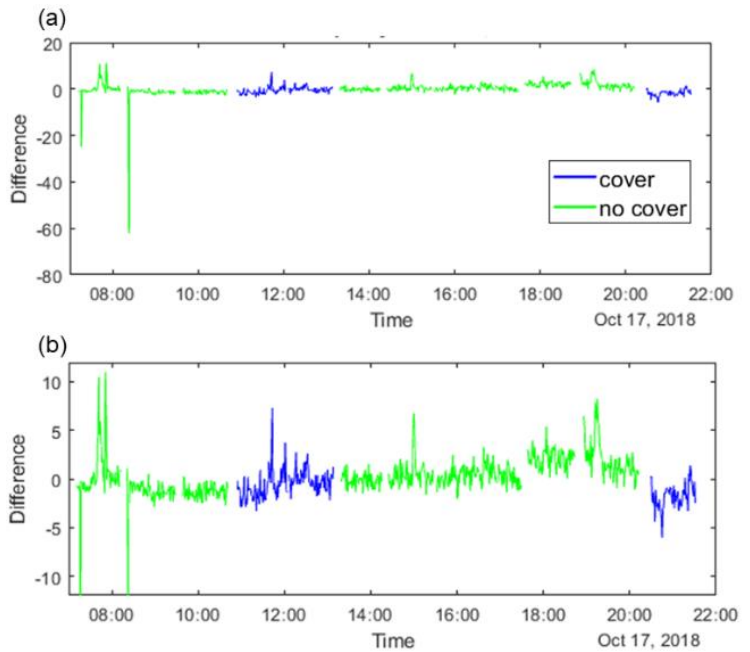

Fig. 2. Differences of $\mathrm{PM}_{2.5}$ concentrations between Honeywell sensors with cover and without cover (a) in full range and (b) in constricted range.
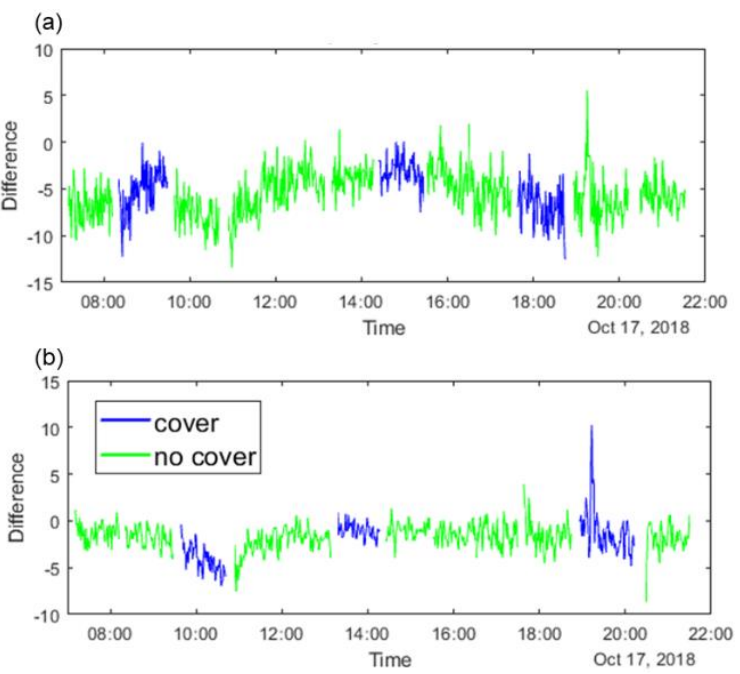

Fig. 3. Differences of $\mathrm{PM}_{2.5}$ concentrations between (a) Plantower and (b) Winsen sensors with cover and without cover.

The outliers were recorded during the measurements as none of the Honeywell sensors were under protective cover (no cover). Fig. $2 \mathrm{~b}$ do not shows the outliers, the differences can be seen between $11.0 \mu \mathrm{g} / \mathrm{m}^{3}$ and $-6.0 \mu \mathrm{g} / \mathrm{m}^{3}$, resulting a $17.0 \mu \mathrm{g} / \mathrm{m}^{3}$ range. With the outliers this range is $72.9 \mu \mathrm{g} / \mathrm{m}^{3}$. Fig. 3 (a) shows the Plantower results, the measured difference range 
was $18.9 \mu \mathrm{g} / \mathrm{m}^{3}$. Fig. $3 \mathrm{~b}$ shows the Winsen results, the measured difference range was $18.8 \mu \mathrm{g} / \mathrm{m}^{3}$. Outliers were not found during Plantower and Winsen tests and the concentration reading differences between the sensors are small. The results show that the protective cover does not affect the sensitivity of the sensors. Further analysis was carried out to determine the probability density functions of the normal distribution of the differences (Fig. 5). Compared the measurements made with cover to the measurements with no cover, significant difference can be seen only in the case of Honeywell (Fig. 5a), which is caused by the outlier values (Fig. 2a). If we ignore functions with the outliers the cover and no cover functions are near to each other expect the long term no covered function, which means that the outlier values occur in long term too. All functions of the Plantower and Winsen sensors are shifted a little under $0 \mu \mathrm{g} / \mathrm{m}^{3}$, but still inside the range of $-15-15 \mu \mathrm{g} / \mathrm{m}^{3}$ (Fig. $5 \mathrm{~b}$ and $5 \mathrm{c}$ ). The Honeywell is less reliable and consistence than Plantower or Winsen.

The recorded $\mathrm{PM}_{2.5}$ values were averaged to minutely and hourly concentration as simple moving average. Fig. 6 (a) illustrates the change in humidity and minutely $\mathrm{PM}_{2.5}$ as a function of time. RH changes between $53-96 \%$ based on the measurement of OLM station. The RH was $95 \%$ or higher during $42 \%$ of the sampling period. Fig. 6 shows minutely (b) and hourly (c) $\mathrm{PM}_{2.5}$ values of Honeywell and OLM device. It can be observed on Fig. 6 that in case of low humidity the concentration values of the sensor are close to the OLM values, while in case of high humidity it differs significantly in positive direction. The Honeywell sensor does not compensate for the change in humidity, either hardware or software, which greatly affects the size and reflective capacity of PM.

Table 3 contains the correlation coefficients between the $\mathrm{PM}_{2.5}$ concentrations of Honeywell sensor and OLM device. The hourly values are correlating better than minutely values because of the data aggregation. Correlation coefficients of values under $90 \% \mathrm{RH}$ are $\approx 0.3$ higher than over $90 \% \mathrm{RH}$.

Table 3. Correlation between Honeywell sensor and OLM device in full time, under and over $90 \%$ $\mathrm{RH}$.

\begin{tabular}{|c|c|c|c|}
\hline Correlation coefficient & R & $\mathbf{R}(\mathbf{R H}<\mathbf{9 0} \%)$ & $\mathbf{R}$ (RH > 90\%) \\
\hline Minutely $\mathrm{PM}_{2.5}$ & 0.48 & 0.58 & 0.35 \\
\hline Hourly $\mathrm{PM}_{2.5}$ & 0.58 & 0.80 & 0.45 \\
\hline
\end{tabular}



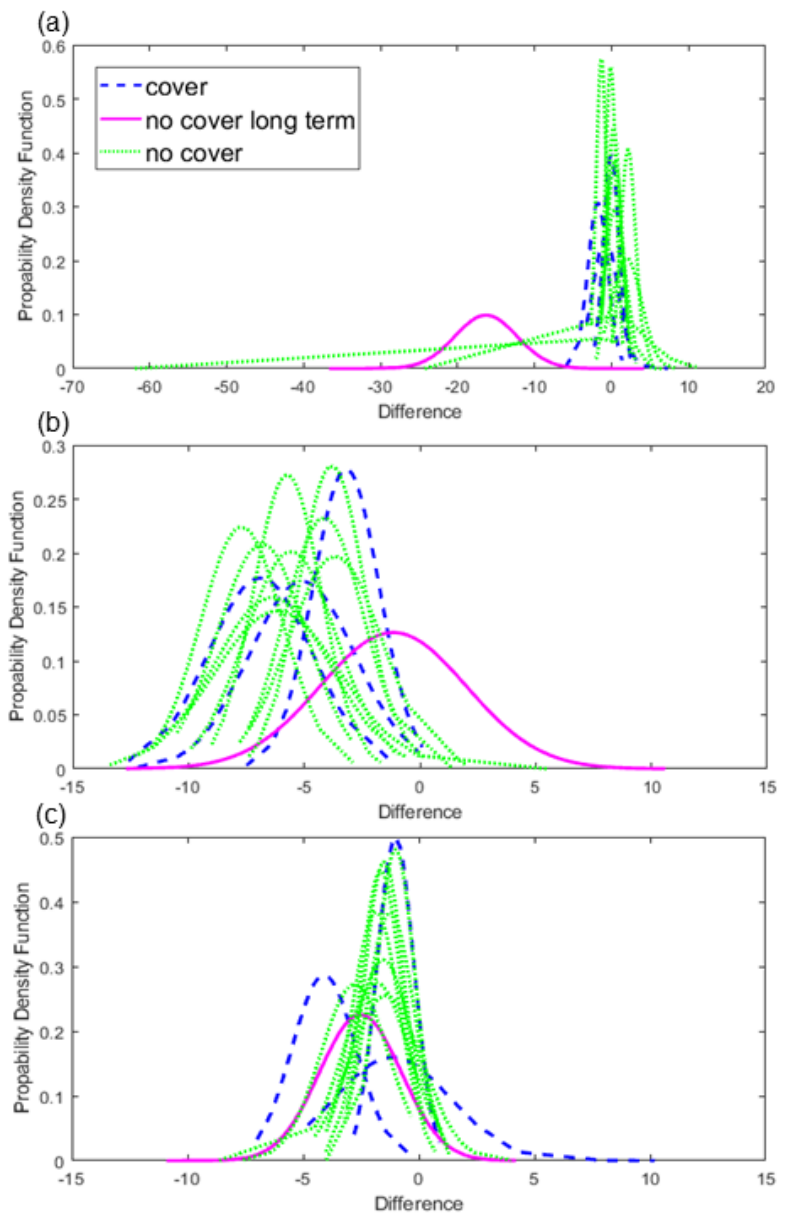

Fig. 5. Probability density functions of (a) Honeywell, (b) Plantower and (c) Winsen sensors differences with cover and without cover. 


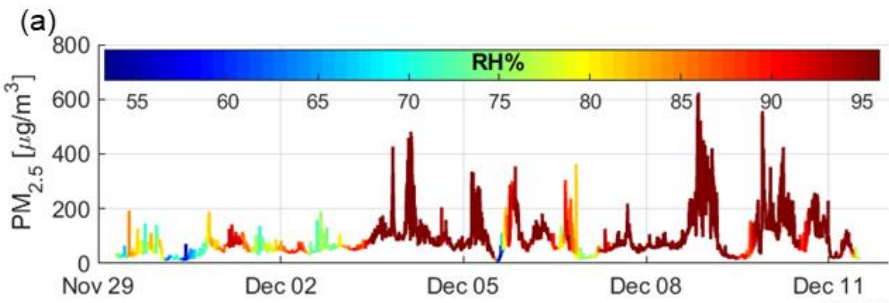

(b)

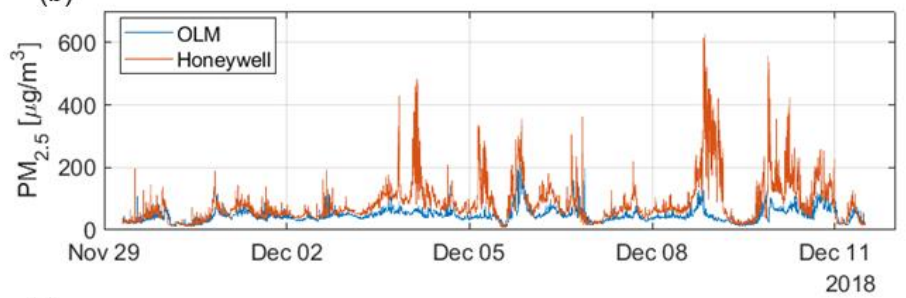

(c)

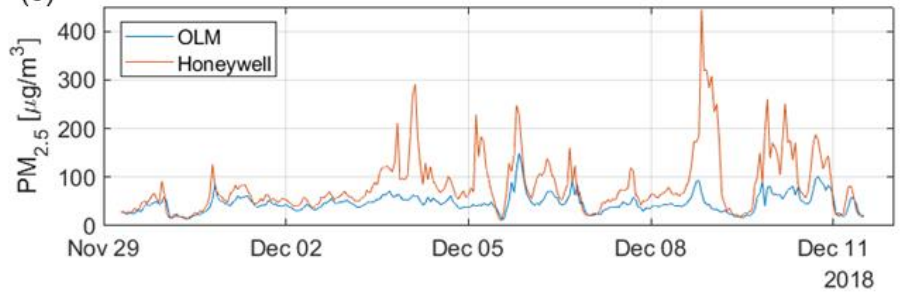

Fig. 6. Illustration of (a) Honeywell $\mathrm{PM}_{2.5}$ concentrations and $\mathrm{RH}$ values, (b) comparison of minutely $\mathrm{PM}_{2.5}$ values of Honeywell and OLM device, (c) comparison of hourly PM2.5 values of Honeywell and OLM device.

\section{Conclusion}

Three different types of sensors from various aspects including reproducibility, design variations, sensors comparison and humidity influence were tested. The effect of a lamellate protective cover is negligible. The difference between the Honeywell sensors with and without the protective cover shows some outliers that were caused by the sensor failure. The Plantower and Winsen are more consistent. Long-term measurement shows that the Honeywell sensor is correlating well to the concentration values of the OLM station in case of low humidity. Future research will be focused on the effect of environmental parameters to the LCS. Our goal is to develop an artificial intelligence based on-filed calibration method that allows us to consider all environmental conditions, time of day, season, heating and non-heating periods. To have enough data for deep learning technique at least one-year long measurement needed from the examined area.

Supported by the ÚNKP-18-3-I-ME/29. New National Excellence Program of the Ministry of Human Capacities.

\section{References}

1. A. Valavanidis, K. Fiotakis, J. Environ. Sci. Health C 26, 339-362 (2008) 
2. J. Wu, W. Cheng, J. Environ. Sci. Manag. 21, 100-109 (2018)

3. O. Jolliet, A. Antón, In. J. Life Cycle Assess. 23, 1-19 (2018)

4. H. He, X.-Z. Liang, Atmos. Environ. 179, 166-176 (2018)

5. J. Lepeule, F. Laden, Environ. Health Perspect. 120, 965-70 (2012)

6. Air quality criteria for particulate matter, vol. 3: US Environmental Protection Agency, Office of Research and Development, National Center for Environmental Assessment (1996)

7. Official Journal of the European Union (2008)

8. 306/2010. (XII. 23.) Korm. rendelet a levegő védelméröl, ed. Magyar Közlöny

9. WHO, Air Quality Guidelines: Global Update 2005. Particulate Matter, Ozone, Nitrogen Dioxide and Sulfur Dioxide: World Health Organization (2006)

10. Ambient Air Monitoring Reference and Equivalent Methods, in Federal Register 40 CFR Parts, ed: US EPA, (1997)

11. 12341:2014, Determination of the $\mathrm{PM}_{10}$ fraction of suspended particulate matter. Reference method and field test procedure to demonstrate reference equivalence of measurements methods, in Air Quality, ed: BSI, (2014)

12. C. A. Noble, R. W. Vanderpool, Aerosol. Sci. Technol. 34, 457-464 (2001)

13. J. Bol, W. Heinze, Method of measuring the concentration and/or size of suspended particles by forward scattering of light (Google Patents, 1972)

14. E. S. Macias, R. B. Husar, Environ. Sci. Technol. 10, 904-907 (1976)

15. H. Patashnick, E. G. Rupprecht, J. Air Waste Manag. Assoc. 41, 1079-1083 (1991)

16. CEN-Technical Bodies-CEN/TC 264/WG 42 2018, Available: https://standards.cen.eu/dyn/www/f?p=CENWEB:7:0::::FSP_ORG_ID:2012773\&cs=1 FD71819F25D74834BB38751B78ACE16D

17. M. Badura, P. Batog, J. Sensors, 2018 (2018)

18. Y. Wang, J. Li, Aerosol. Sci. Technol. 49, 1063-1077 (2015)

19. C. Borrego, A. Costa, Atmos. Environ. 147, 246-263 (2016)

20. A. L. Clements, W. G. Griswold, Sensors 17, 2478 (2017)

21. J.-B. Renard, F. Dulac, Atmos. Meas. Tech. 9, 1721-1742 (2016)

22. J.-B. Renard, F. Dulac, Atmos. Meas. Tech. 8, 1261-1299 (2015)

23. A. L. Northcross, R. J. Edwards, Environ. Sci. Process Impacts 15, 433-439 (2013)

24. M. Canu, B. Galvis, Understanding the Shinyei PPD24NS low-cost dust sensor (in: IEEE International Conference on Environmental Engineering, 1-10, 2018)

25. L.-A. Tortajada-Genaro, E. Borrás, J. Environ. Monitor. 13, 1017-1026 (2011)

26. G. Allen, C. Sioutas, J. Air Waste Manag. Assoc. 47, 682-689 (1997)

27. R. Jayaratne, X. Liu, Atmos. Meas. Tech. 11, 4883-4890 (2018)

28. L. R. Crilley, M. Shaw, Atmos. Meas. Tech. 709-720 (2018)

29. R. Williams, T. Conner, Performance Evaluation of the United Nations Environment Programme Air Quality Monitoring Unit (EPA - Office of Research and Development National Exposure Research Laboratory, Washington DC, 2017) 